\title{
Totally thoracoscopic repair of ventricular septal defect: A short-term clinical observation on safety and feasibility
}

\author{
Zeng-Shan Ma, MD, ${ }^{\mathrm{a}}$ Ming-Feng Dong, MD, ${ }^{\mathrm{a}}$ Qiu-Yang Yin, MD, ${ }^{\mathrm{a}} \mathrm{Zhi}-$ Yu Feng, MD, ${ }^{\mathrm{a}}$ and \\ Le-Xin Wang, $\mathrm{MD}, \mathrm{PhD}^{\mathrm{a}, \mathrm{b}}$
}

Objectives: We sought to investigate the feasibility and safety of totally thoracoscopic repair of a ventricular septal defect.

\begin{abstract}
Methods: Totally thoracoscopic repair of a perimembranous ventricular septal defect was performed in 36 patients (16 male patients; age, 5-19 years; average age, $10.2 \pm 4.5$ years). Patients with a pulmonary arterial systolic pressure of $60 \mathrm{~mm} \mathrm{Hg}$ or greater or with supracristal or muscular ventricular septal defects were excluded. An additional 16 patients undergoing open-chest ventricular septal defect repair were selected as a control group. Through 3 port incisions in the right chest, pericardiotomy, bicaval occlusion, atriotomy, and ventricular septal defect repair were performed by a surgeon by means of thoracoscopy.
\end{abstract}

Results: The cardiopulmonary bypass and aortic crossclamp times were $66.2 \pm 21.3$ and $36.4 \pm 8.2$ minutes, respectively. The length of stay in the intensive care unit was $20.0 \pm 4.1$ hours. There were no mortalities and no major complications. Transesophageal echocardiographic analysis $5.2 \pm 3.6$ months after the operation showed complete closure of the defect without residual shunt. The intensive care unit ( $17 \pm 2$ vs $25 \pm 5$ hours, $P=.01$ ) or postoperative hospital ( $4.2 \pm 1.1$ vs $6.7 \pm 2.1$ days, $P=.03)$ stays in the thoracoscopic group were shorter than in the control group. The percentage of patients who required postoperative opioid analgesics in the thoracoscopic group was lower than in the control group $(37.5 \%$ vs $87.5 \%, P=.001)$.

Conclusions: Totally thoracoscopic repair of a perimembranous ventricular septal defect is feasible and safe for older children. This technique is associated with a reduced intensive care and hospital stay in comparison with conventional ventricular septal defect repair. (J Thorac Cardiovasc Surg 2011;142:850-4)

Minimally invasive cardiac surgery has been used in recent years for atrial septal defect (ASD) or ventricular septal defect (VSD) closure..$^{1-3}$ These procedures are characterized by the performance of complex cardiac surgical procedures through smaller incisions and are often facilitated by computers and an endoscopic camera to guide the manipulation of surgical instruments through small thoracic incisions. ${ }^{4}$ In recent years, totally endoscopic procedures have been reported to be a safe and effective method, with a rapid recovery of quality of life and lower pain levels compared with both median sternotomy and minithoracotomy. ${ }^{5-8}$

Totally endoscopic procedures remain highly complex and require the assistance of computer and robotic technologies. These procedures have been used for the repair of simple con-

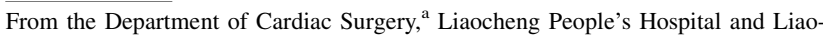
cheng Clinical School of Taishan Medical University, Liaocheng, China; and the School of Biomedical Sciences, ${ }^{\text {b }}$ Charles Sturt University, Wagga Wagga, Australia.

Disclosures: Authors have nothing to disclose with regard to commercial support. Received for publication Sept 9, 2010; revisions received Dec 22, 2010; accepted for publication March 1, 2011; available ahead of print April 1, 2011.

Address for reprints: Le-Xin Wang, MD, PhD, School of Biomedical Sciences, Charles Sturt University, Wagga Wagga, NSW 2678, Australia (E-mail: lwang@ csu.edu.au).

0022-5223/\$36.00

Crown Copyright $\odot 2011$ Published by Elsevier Inc. on behalf of The American Association for Thoracic Surgery.

doi:10.1016/j.jtcvs.2011.03.001
}

genital defects, such as ASDs. ${ }^{5-8}$ The effectiveness and safety of totally endoscopic repair of a VSD have not been extensively investigated. Moreover, almost all the currently reported totally endoscopic repairs of ASDs were assisted by the robotic Da Vinci Surgical System. ${ }^{5-8}$ The aim of this study was to describe the feasibility, indications, limitations, and problems of totally thoracoscopic repair of a VSD through a 3-port entry approach without the aid of a robotically assisted surgical system.

\section{MATERIALS AND METHODS \\ Patient Selection}

This study was approved by the Institutional Review Board of Liaocheng People's Hospital. Written informed consent was obtained from all participants before the study. The total annual number of pediatric operations in the department of cardiac surgery is approximately 250. With smaller children ( $\leq 5$ years old) we perform conventional open-chest VSD closure. Open-chest VSD closure is also performed in patients with supracristal (conal septal, infundibular, subpulmonic, subarterial, subarterial doubly committed, and outlet) or muscular VSDs. For this study, we screened 85 patients with VSDs between June 2009 and March 2010, of whom 36 met the selection criteria and provided written consent for thoracoscopic closure. In the same time period, 16 patients who met the criteria for thoracoscopic closure but opted to receive conventional open-chest surgery were registered as a control group.

For thoracoscopic VSD closure, both of the following 2 selection criteria must be met: (1) presence of a perimembranous VSD of any size and (2) patient older than 5 years with a body weight of more than $20 \mathrm{~kg}$. Exclusion criteria are any one of the following: (1) supracristal or muscular 


\section{Abbreviations and Acronyms \\ $\mathrm{ASD}=$ atrial septal defect \\ $\mathrm{CPB}=$ cardiopulmonary bypass \\ $\mathrm{VSD}=$ ventricular septal defect}

VSD; (2) pulmonary arterial systolic pressure (measured by means of echocardiographic analysis) of $60 \mathrm{~mm} \mathrm{Hg}$ or greater; (3) history of lung disease, right-sided chest operation, or adhesions of the right pleural membrane; (4) concurrent cardiovascular disease or chronic illnesses; and (5) inability to provide informed consent.

\section{Anesthesia}

After induction of general anesthesia, a left-sided double-lumen endotracheal tube $(\geq 50 \mathrm{~kg})$ or single-lumen endotracheal tube $(<50 \mathrm{~kg})$ was placed to allow for single-lung ventilation. The respiration rate was set between 18 and 30 breaths/min, and the arterial oxygen saturation rate was maintained at greater than $97 \%$. After the induction of general anesthesia, a transesophageal echocardiographic probe was inserted to monitor the VSD repair.

\section{Surgical Techniques}

The patient was positioned in a $15^{\circ}$ to $20^{\circ}$ left lateral decubitus position. After systemic heparinization, the right femoral artery and vein were accessed through an oblique incision along the inguinal crease, as previously reported by Bonaros and colleagues. ${ }^{7}$ A 24F/29F Carpentier double-lumen catheter (Medtronic, Minneapolis, Minn) was inserted through the right femoral vein into the inferior and superior venae cavae. The bypass circuit was completed by positioning a $17 \mathrm{~F}$ or $21 \mathrm{~F}$ catheter (Medtronic) in the abdominal aorta through the right femoral artery.

Three small incisions (ports) were made on the right side of the chest (Figure 1). Port $1(1-1.5 \mathrm{~cm})$ was located in the fourth intercostal space on the right side of the sternum (Figure 1). This port was for the insertion of surgical instruments, such as tissue forceps or suture needles, with the left hand (for a right-handed operator). Port $2(1-1.5 \mathrm{~cm})$ was for the entry of instruments, such as scissors, handled by the right hand of the operator. It is located in the sixth intercostal space on a midclavicular line (Figure 1). Port $3(1.5-2.0 \mathrm{~cm})$ was located in the fifth intercostal space on the right midaxillary line (Figure 1). This port was for the placement of an endoscopic camera or thoracoscopy. A self-made plastic retractor was inserted into each of the 3 ports to keep the ports open and to facilitate the insertion or withdrawal of the instruments or thoracoscopy (Figure 2). A conventional Olympus OTV-S7 thoracoscope (Olympus Corp, Tokyo, Japan) was used in this study. Other surgical instruments, such as forceps or scissors, were conventional instruments for thoracoscopic surgery (Scanlan International, St Paul, Minn).

Once the 3 ports were secured, pericardiotomy was performed, and 3 to 4 sutures were placed to suspend the pericardium. Caval snares were placed in the superior and inferior venae cavae to install total cardiopulmonary bypass (CPB). After $\mathrm{CPB}$ initiation and cooling to $32^{\circ} \mathrm{C}$, the thoracoscopy was placed through port 2 to visualize the root of the aorta. An aortic crossclamp was positioned on the ascending aorta (Figure 3). A needle was inserted through port 3 to the aortic root for the delivery of cold St Thomas cardioplegic solution to achieve cardiac arrest (Figure 3). The thoracoscopy was repositioned through port 3 to visualize the right atrium. A tissue forceps and a scissors were entered through ports 1 and 2, respectively (Figure 2). After snaring of the superior and inferior venae cavae, the right atrium was opened from a site parallel to the atrioventricular annulus, and 4 stay sutures were placed on the incision to expose the intra-atrial structure. A 3-mm incision was made on the fossa ovalis for the insertion of the left

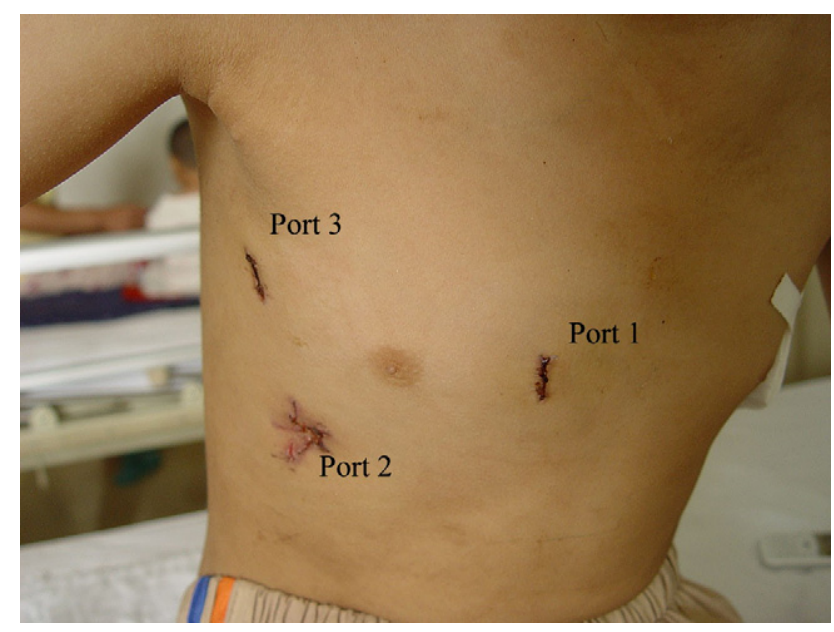

FIGURE 1. Location of the 3 ports on the right chest wall.

atrial drainage tube. The tricuspid valves were pulled apart to expose the VSD. For a defect of less than $6 \mathrm{~mm}$, direct sutures (4-0 Proline; Ethicon, Somerville, NJ) were used for closure (Figure 4). A bovine patch (Bairen Med Pharma Co, Beijing, China) was used to repair defects of $6 \mathrm{~mm}$ or larger with running Prolene sutures. The DeVega technique was used to repair tricuspid valve regurgitation.

After VSD closure, the incisions in the fossa ovalis and the right atrium were closed. Deairing was performed through the perfusion needle at the root of the aorta through negative pressure. The aortic crossclamp was released, and the patient was rewarmed. The patient was weaned from CPB. Integrity of the VSD closure was confirmed by means of transesophageal echocardiographic analysis, and protamine sulfate (1:1) was administered. After adequate hemostasis was achieved, all instruments were removed from the chest, and a $24 \mathrm{~F}$ chest tube was inserted in the right pleural space through port 2 for drainage. Finally, the cannulas in the right femoral vein and artery were removed, and incisions on the blood vessels were closed with sutures.

Sixteen consecutive patients undergoing open-chest repair for perimembranous VSD were selected between June 2009 and March 2010 to compare operational data and the requirement for postoperative analgesics between conventional and thoracoscopic VSD closure. These patients were matched in terms of demographics and VSD type with the last 16 patients in the thoracoscopic group.

\section{Perioperative Management}

Before the operation, education and counseling were provided to all participants on surgical techniques, possible clinical outcomes, potential complications, and postoperative self-care measures. Lung function tests were routinely performed in all patients before the operation. The lungs were inflated every 20 minutes during the operation. After the operation, patients were monitored in the intensive care unit overnight and received low-frequency, high-volume mechanical ventilation with a peak endexpiratory pressure of 3 to $5 \mathrm{~cm} \mathrm{H}_{2} \mathrm{O}$. Bedside chest radiographic analysis was routinely performed in the intensive care unit to exclude complications in the lungs. Furosemide ( $1 \mathrm{mg} / \mathrm{kg}$ administered intravenously once daily) and methylprednisolone $(0.5 \mathrm{mg} / \mathrm{kg}$ administered intravenously once daily) were used in all patients to prevent pulmonary edema. Mechanical ventilation was ceased once patients' hemodynamics and spontaneous respiration stabilized. Nonsteroidal anti-inflammatory drugs were prescribed to all patients for postoperative pain relief. For patients with severe pain not relieved by simple analgesics, opioid analgesics (intravenous fentanyl) were also provided. 


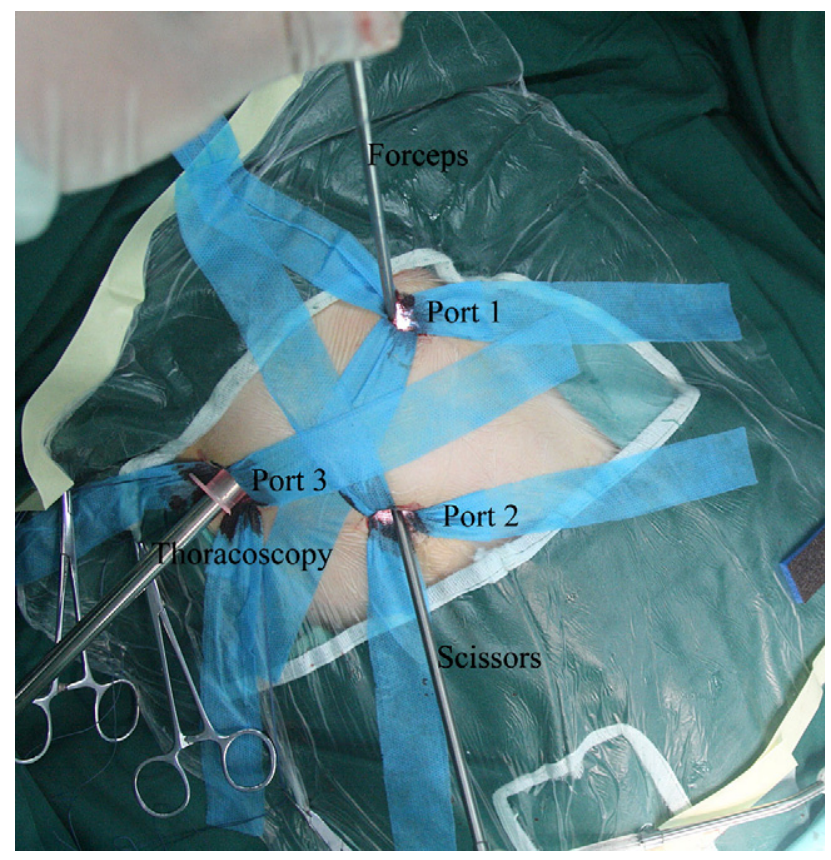

FIGURE 2. Function of the 3 ports.

\section{Statistical Analysis}

SPSS software version 13.0 (SPSS, Inc, Chicago, Ill) was used for the statistical analysis. Quantitative variables are expressed as means \pm standard deviations. Differences between multiple groups were compared by means of 1-way analysis of variance. Categorical variables were compared by using $\chi^{2}$ tests.

\section{RESULTS}

Eighty-five patients were initially screened, and 36 were recruited to this study. The main reasons for exclusion were as follows: (1) less than 5 years old or body weight less than $20 \mathrm{~kg}(\mathrm{n}=35)$; (2) older than 5 years but the femoral artery or vein was too small for canalization with a $10 \mathrm{~F}$ catheter, as determined by means of Doppler ultrasound examination, $(\mathrm{n}=2)$; (3) pulmonary artery pressure of $60 \mathrm{~mm} \mathrm{Hg}$ or greater $(\mathrm{n}=9)$; and (4) history of lung disease or rightsided chest operation preventing insertion of a thoracoscope $(\mathrm{n}=3)$.

Of the selected patients, there were 16 male and $20 \mathrm{fe}$ male patients with a mean age of $10.2 \pm 4.5$ years (range, 5-19 years). The mean body weight was $30.4 \pm 10.6 \mathrm{~kg}$ (range, 18-68 kg). Echocardiographic examination showed perimembranous VSDs in all. The size of the defect ranged from 4 to $14 \mathrm{~mm}$. Seven patients had mild pulmonary hypertension (pulmonary arterial pressure, $30-40 \mathrm{~mm} \mathrm{Hg}$ ), and 3 had moderate pulmonary hypertension (pulmonary arterial pressure, $40-60 \mathrm{~mm} \mathrm{Hg}$ ). Four patients also had tricuspid regurgitation caused by right ventricular dilation. Valvuloplasty with the DeVega technique was performed in 2 of the 4 patients immediately after VSD repair in the same procedure. Follow-up echocardiographic studies showed no tricuspid regurgitation in these 2 patients.

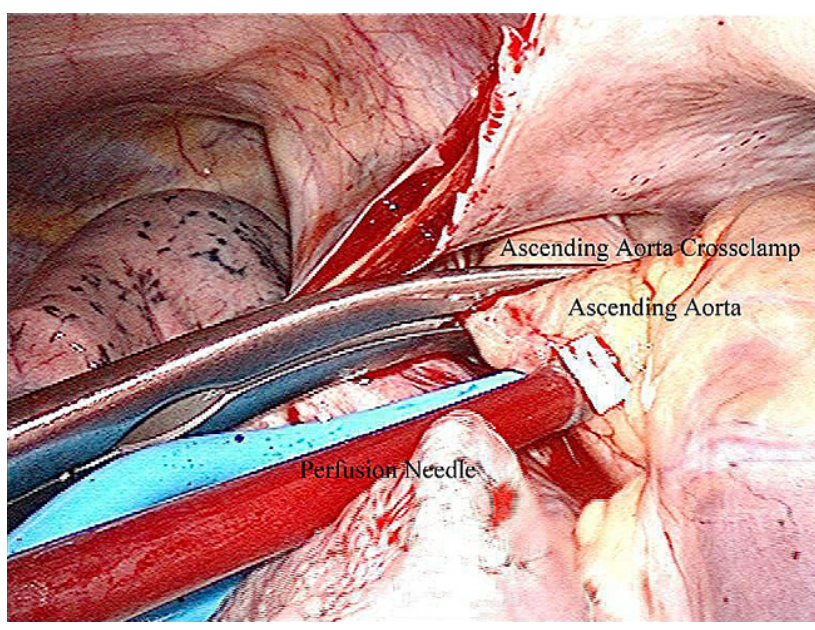

FIGURE 3. Aortic crossclamp and perfusion of cardioplegic solution.

In the early stage of this study (the first 10 patients), 1 patient had bleeding caused by injury to the inferior vena cava and right atrium. Another patient had bleeding from the ascending aorta, where a needle was inserted to perfuse cardioplegic solution. In both cases the chest incision at port 2 was extended to 4 to $5 \mathrm{~cm}$ for better visualization of the bleeding sites, and bleeding was successfully stopped with sutures. Thoracoscopic VSD repair was successfully completed after the bleeding from the inferior vena cava or ascending aorta was stopped.

All patients survived the operation and were discharged from the hospital in 2 to 6 days. No patient in this cohort underwent reoperation for bleeding after the VSD repair. The mean CPB time was $66.2 \pm 21.3$ minutes (range, 54-142 minutes). The mean aortic crossclamp time was $36.4 \pm$ 8.2 minutes (range, 25-57 minutes). Once the aortic clamp was removed, heart beat resumed spontaneously in 27 patients. In 9 patients $50 \mathrm{~W}$ DC shock through the chest

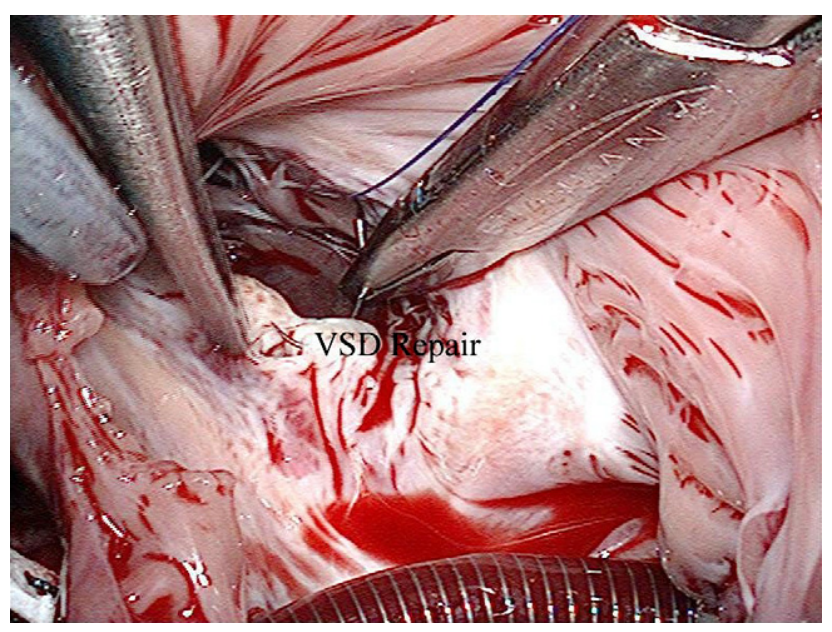

FIGURE 4. Closure of ventricular septal defect (VSD). 
TABLE 1. Comparison of operational data between the patients undergoing thoracoscopic ventricular septal defect closure

\begin{tabular}{lcccc}
\hline & $\begin{array}{c}\text { Patients } \\
\mathbf{1 - 1 0}\end{array}$ & $\begin{array}{c}\text { Patients } \\
\mathbf{1 1 - 2 0}\end{array}$ & $\begin{array}{c}\text { Patients } \\
\mathbf{2 1 - 3 6}\end{array}$ & $\begin{array}{c}\boldsymbol{P} \\
\text { value }\end{array}$ \\
\hline Total operation time (min) & $147 \pm 20$ & $130 \pm 5$ & $112 \pm 10$ & .003 \\
CPB (min) & $80 \pm 17$ & $63 \pm 5$ & $55 \pm 3$ & .002 \\
Aortic crossclamp time (min) & $46 \pm 7$ & $34 \pm 5$ & $28 \pm 3$ & .01 \\
Mechanical ventilation time (h) & $5.0 \pm 1.4$ & $3.0 \pm 0.6$ & $3.0 \pm 0.6$ & .01 \\
Intensive care stay (h) & $28 \pm 4$ & $22 \pm 5$ & $17 \pm 2$ & .01 \\
\hline Patients 21 to 36 included the 2 patients who underwent valvuloplasty during the \\
same procedure. $C P B$, Cardiopulmonary bypass.
\end{tabular}

wall was performed to cardiovert the fibrillating heart back to sinus rhythm. The mean mechanical ventilation time was $4.0 \pm 1.1$ hours (range, $2-19$ hours), and the mean duration of intensive care unit stay was $20.0 \pm 4.1$ hours (range, 20-28 hours). The total operation time, CPB time, aortic crossclamp time, mechanical ventilation time, duration of intensive care stay, and complication rates of the first, second, and third groups of 10 patients are listed in Table 1. There was a significant reduction in total operation time, CPB time, aortic crossclamp time, and duration of intensive care unit stay in the last 16 patients $(P \leq .01)$.

In all patients transesophageal echocardiographic analysis immediately after VSD repair showed complete closure with no residual shunt. Two $(5.6 \%)$ patients experienced arrhythmia, and 1 had a high degree of atrioventricular conduction block, which spontaneously recovered within 24 hours after the operation. The other patient had atrial fibrillation after VSD repair, but sinus rhythm returned after 52 hours. One $(2.8 \%)$ patient had right pulmonary atelectasis, from which the patient recovered in 2 days after physiologic therapy on the chest. There was a significant difference in complication rates between the first 20 and the last 16 patients $(15.0 \%$ vs $0 \%, P<.01)$.

Three $(8.3 \%)$ patients required blood transfusion of 400 $\mathrm{mL}$ each during the procedure. The total volume of chest drainage ranged from 30 to $460 \mathrm{~mL}$ (mean, $65 \pm 29 \mathrm{~mL}$ ). Patients have been followed up for $5.2 \pm 3.9$ months (range, 3-12 months), with no signs of residual shunt on transthoracic echocardiographic analysis. There were no complications from the operation. Patients resumed work or schooling between 14 and 23 days (median, 16 days) after the operation.

As shown in Table 2, there was no significant difference in age, sex, total operation time, CPB time, aortic crossclamp time, and mechanical ventilation time between the thoracoscopic and control groups $(P>.05)$. In the thoracoscopic group the blood loss during the operation was significantly less than in the control group $(P<.01)$, and the intensive care unit or total hospital stays were shorter $(P<.05)$. In the thoracoscopic group 6 patients required intravenous fentanyl $\left(5-10 \mu \mathrm{g} \cdot \mathrm{kg}^{-1} \cdot \mathrm{h}^{-1}\right)$ for 1 to 2 days, and the remainder were treated with simple analgesics, mostly
TABLE 2. Comparison of operational data between the thoracoscopic (study) and control groups

\begin{tabular}{lccc}
\hline & $\begin{array}{c}\text { Study group } \\
(\mathbf{n}=\mathbf{1 6})\end{array}$ & $\begin{array}{c}\text { Control group } \\
(\mathbf{n}=\mathbf{1 6})\end{array}$ & $\begin{array}{c}\boldsymbol{P} \\
\text { value }\end{array}$ \\
\hline Age (y) & $7 \pm 3$ & $8 \pm 4$ & .11 \\
Male sex & $10(62.5 \%)$ & $9(56.3 \%)$ & .12 \\
Total operation time (min) & $112 \pm 10$ & $126 \pm 30$ & .053 \\
CPB (min) & $55 \pm 3$ & $56 \pm 11$ & .123 \\
Aortic crossclamp time (min) & $28 \pm 3$ & $26 \pm 5$ & .098 \\
Blood loss (mL) & $50 \pm 22$ & $110 \pm 33$ & .001 \\
Mechanical ventilation (h) & $3.0 \pm 0.6$ & $3.6 \pm 1$ & .12 \\
Intensive care unit stay (h) & $17 \pm 2$ & $25 \pm 5$ & .01 \\
Hospital stay (d) & $3.7 \pm 0.4$ & $6.1 \pm 0.6$ & .03 \\
Complications & 0 & $1(6.2 \%)^{*}$ & $\mathrm{NS}$ \\
Patients requiring opioid & $6(37.5 \%)$ & $14(87.5 \%)$ & .001 \\
$\quad$ & & & \\
analgesics & & &
\end{tabular}

The study group included patients 21 to 36 . $C P B$, Cardiopulmonary bypass. *Postoperative bleeding that did not require reoperation.

paracetamol. In the control group fentanyl was administered to $14(87.5 \%)$ patients $(P<.01)$ for 1 to 5 days after the operation, and the remaining patients received nonsteroidal anti-inflammatory drugs for pain relief.

\section{DISCUSSION}

The computerized telemicromanipulator or surgical robot is a relatively new device for minimally invasive cardiac surgery. Using this device, surgeons can manipulate small instruments through small chest incisions to perform procedures previously possible only with open exposure. ${ }^{2}$ The totally endoscopic technique has been used for ASD repair, ${ }^{6-10}$ treatment of atrial fibrillation, ${ }^{10}$ and coronary bypass grafting. ${ }^{11}$ Although the efficacy and safety of the totally endoscopic technique are still under evaluation, recent clinical results on ASD repair were quite encouraging because the operation could be performed safely and with no need for conversion to full sternotomy or minithoracotomy in all reported cases. ${ }^{5-9}$

A potential disadvantage that might hinder the widespread use of the current totally endoscopic technique is the reliance on the robotically assisted surgical system. The complexity and costs of these computerized systems might be an issue for some hospitals or patients, particularly those from developing countries. In this study, based on the previously reported endoscopic techniques, ${ }^{5-9}$ we derived a totally thoracoscopic approach for the closure of a perimembranous VSD without the need for robotic assistance. The plastic retractors we made for the small chest incisions greatly eased the insertion and withdrawals of surgical instruments or thoracoscopy through the 3 ports on the right chest. Successful repair of the perimembranous VSD was achieved in all patients. There were no life-threatening complications and no need for converting to full sternotomy or minithoracotomy. 
These data suggest that totally thoracoscopic repair of a perimembranous VSD without robotic assistance is feasible and safe.

As with robotically assisted endoscopic techniques, our totally thoracoscopic approach was also associated with learning-curve issues. In this study all procedures were performed by a single operator (Z-S.M.). As shown in Table 1, after the first 20 patients, the total operation times, CPB times, and aortic crossclamp times were reduced to 112,55 , and 28 minutes, respectively. To date, there are few published data on totally thoracoscopic VSD repair that we can use for comparison. Reports on robotically assisted endoscopic repair of ASDs showed CPB times of 122 to 135 minutes and aortic crossclamp times of 32 to 70 minutes. $^{5-9}$ Therefore our operational data are compared favorably with those of other groups, even though VSD repair is technically more challenging than ASD closure. These results suggest that after 20 patients, an operator can achieve the competence for totally thoracoscopic VSD repair, even without robotic assistance.

One of the potential limitations in this single-center study is that only a small group of patients were involved and follow-up was relatively short (3-12 months). The longterm efficacy and safety of this technique are yet to be determined in a large number of patients. Only older $(>5$ years) and larger $(>20 \mathrm{~kg})$ patients were included in this study. Younger patients and those with smaller body weight or size were not suitable for the current thoracoscopic technique because peripheral CPB was difficult to establish in these patients as a result of relatively small femoral arteries or veins. Finally, this totally thoracoscopic approach is only suitable for perimembranous VSD closure. Supracristal or muscular VSDs were difficult to access through the chest ports. Therefore this type of VSD is better suited for conventional open-chest closure.
In conclusion, in patients with perimembranous VSDs, totally thoracoscopic repair without a robotically assisted surgical system appears feasible and safe. This novel technique is associated with a reduced intensive care and hospital stay in comparison with conventional surgical VSD repair.

\section{References}

1. Xing Q, Pan S, An Q, Zhang Z, Li J, Li F, et al. Minimally invasive perventricular device closure of perimembranous ventricular septal defect without cardiopulmonary bypass: multicenter experience and mid-term follow-up. J Thorac Cardiovasc Surg. 2010;139:1409-15.

2. Vistarini N, Aiello M, Mattiucci G, Alloni A, Cattadori B, Tinelli C, et al. Portaccess minimally invasive surgery for atrial septal defects: a 10-year singlecenter experience in 166 patients. J Thorac Cardiovasc Surg. 2010;139:139-45.

3. Doll N, Walther T, Falk V, Binner C, Bucerius J, Borger MA, et al. Secundum ASD closure using a right lateral minithoracotomy five-year experience in 122 patients. Ann Thorac Surg. 2003;75:1527-31.

4. Falk V, Walther T, Autschbach R, Diegeler A, Battellini R, Mohr FW. Robot-assisted minimally invasive solo mitral valve operation. J Thorac Cardiovasc Surg. 1998;115:470-1.

5. Wimmer-Greinecker G, Dogan S, Aybek T, Khan MF, Mierdl S, Byhahn C, et al. Totally endoscopic atrial septal repair in adults with computer-enhanced telemanipulation. J Thorac Cardiovasc Surg. 2003;126:465-8.

6. Argenziano M, Oz MC, Kohmoto T, Morgan J, Dimitui J, Mongero L, et al. Totally endoscopic atrial septal defect repair with robotic assistance. Circulation. 2003;108(suppl 2):191-4.

7. Bonaros N, Schachner T, Oehlinger A, Ruetzler E, Kolbitsch C, Dichtl W, et al. Robotically assisted totally endoscopic atrial septal defect repair: insights from operative times, learning curves, and clinical outcome. Ann Thorac Surg. 2006;82:687-93.

8. Morgan JA, Peacock JC, Kohmoto T, Garrido MJ, Schanzer BM, Kherani AR, et al. Robotic techniques improve quality of life in patients undergoing atrial septal defect repair. Ann Thorac Surg. 2004;77:1328-33.

9. Torracca L, Ismeno G, Alfieri O. Totally endoscopic computer-enhanced atrial septal defect closure in six patients. Ann Thorac Surg. 2001;72:1354-7.

10. Loulmet DF, Patel NC, Patel NU, Frumkin WI, Santoni-Rugiu F, Langan MN, et al. First robotic endoscopic epicardial isolation of the pulmonary veins with microwave energy in a patient in chronic atrial fibrillation. Ann Thorac Surg. 2004; 78:e24-5

11. de Canniere D, Wimmer-Greinecker G, Cichon R, Van Praet F, SeshadriKreaden U, Falk V. Feasibility, safety, and efficacy of totally endoscopic coronary artery bypass grafting: multicenter European experience. J Thorac Cardiovasc Surg. 2007;134:710-6. 